\title{
KINETICS OF NUCLEIC ACID SYNTHESIS IN THE GROWTH OF AZOTOBACTER VINELANDII
}

\author{
SHIRO NAGAI, YOSHINORI NISHIZAWA AND SHUICHI AIBA \\ The Institute of Applied Microbiology, University of Tokyo, Tokyo
}

(Received April 14, 1969)

The ratio of RNA to DNA concentrations, $C_{R} / C_{D}$, in a culture was used as parameter to define the rates of syntheses of RNA and DNA in Azotobacter vinelandii.

The value of specific rate of change in $C_{2}(=$ dilution rate, $D)$ for the balanced growth of the bacterium was shown by

$$
\mu_{C_{\imath}}=\frac{\alpha_{2}\left\{\frac{C_{R}}{C_{D}}-\left(\frac{C_{R}}{C_{D}}\right)_{0}\right\}}{1-\alpha_{1}\left\{\frac{C_{R}}{C_{D}}-\left(\frac{C_{R}}{C_{D}}\right)_{0}\right\}} \text {; where subscript } 0 \text { denotes the value of }
$$

$C_{R} / C_{D}$ as extrapolated to $\mu_{C_{\imath}}\left(=\mu_{C_{R}}=\mu_{C_{D}}=\mu_{X}\right)=0$. Balanced growth of some bacteria other than $A$. vinelandii showed the same correlation between $\mu_{C_{\imath}}$ and $C_{R} / C_{D}-\left(C_{R} / C_{D}\right)_{0}$.

Regarding the unbalanced growth of this bacterium, which was realized by transferring the culture from the continuous run to a batch and by releasing the limited situation of glucose, a similar correlation was obtained:

$$
\mu_{C_{R}}=\frac{\alpha_{4}\left\{\frac{C_{R}}{C_{D}}-\left(\frac{C_{R}}{C_{D}}\right)_{2}\right\}}{1-\alpha_{3}\left\{\frac{C_{R}}{C_{D}}-\left(\frac{C_{R}}{C_{D}}\right)_{2}\right\}}, \quad \mu_{C_{D}}=\frac{\alpha_{6}\left\{\frac{C_{R}}{C_{D}}-\left(\frac{C_{R}}{C_{D}}\right)_{2}\right\}}{1-\alpha_{5}\left\{\frac{C_{R}}{C_{D}}-\left(\frac{C_{R}}{C_{D}}\right)_{2}\right\}} .
$$

The only difference in the kinetic equations representing the balanced and the unbalanced growth of the bacterium was in its signs and absolute values of the coefficients involved.

The cellular response of Azotobacter vinelandii to a sudden pulse of glucose applied to a glucose-limited chemostatic culture (thereby releasing the limiting situation) was analyzed in our previous work. The semi-logarithmic relationship between the fraction of RNA, $N_{R}$, in cells and the specific growth rate, $\mu_{X}$, was also observed during the unbalanced growth which followed disruption of the steady state condition in the chemostat. A kinetic model which used $N_{R}$ as a parameter coupled this relation between $N_{R}$ and $\mu_{X}$ with the rates of change in the substrate, $S$, and in $N_{R}$. The model represents fairly well the unbalanced growth pattern (1).

The fact emphasized by other workers $(2,3)$ that the cell size and even 
the number of nuclei per cell change depending on the environmental conditions cannot be disregarded. Actually, the cell size of $A$. vinelandii was observed microscopically to exhibit an appreciable change in their balanced growth depending on the dilution rate of the chemostat. However, the cell size, DNA levels, and so forth were less subjected to change during unbalanced growth, which lasted, incidentally, for about $5 \mathrm{hr}$ in various experiments reported previously (1). Accordingly, the previous parametric model using $N_{R}$ as parameter to describe the unbalanced growth of $A$. vinelandii seems justified.

If the rates of syntheses of RNA and DNA are of particular interest, the basic consideration must be $\mathrm{C}_{R} / \mathrm{C}_{D}(=\mathrm{mg} \mathrm{RNA} / \mathrm{mg} \mathrm{DNA})$ rather than $N_{R}$ (=mg $\mathrm{RNA} / \mathrm{mg}$ cell). The ratio $\mathrm{C}_{R} / \mathrm{C}_{D}$ seems more effective than $N_{R}$, because the former parameter $\mathrm{C}_{R} / \mathrm{C}_{D}$ can handle even the case where the cellular content of DNA (in $\mathrm{mg}$, not fraction) undergoes an appreciable change (3). In fact, $\mathrm{C}_{R} / \mathrm{C}_{D}$ has already been suggested by other workers as a measure to evaluate the growth activity of various bacteria (4).

It is the purpose of this paper to derive from $\mathrm{C}_{R} / \mathrm{C}_{D}$ another model defining balanced and unbalanced growth in the culture of $A$. vinelandii. A correlation will be made in this work between $\mathrm{C}_{R} / \mathrm{C}_{D}$ and

$$
\mu_{X}\left(=\mu_{C_{R}} \equiv \frac{1}{C_{R}} \cdot \frac{d C_{R}}{d t}=\mu_{C_{D}} \equiv \frac{1}{C_{D}} \cdot \frac{d C_{D}}{d t}\right),
$$

first for the balanced growth. The specific rates of change in any components of cells are exactly equal in the balanced growth (5).

Secondly, another correlation will be attempted between $\mathrm{C}_{R} / \mathrm{C}_{D}$ and $\mu_{C_{R}}$ or $\mu_{C} C_{D}$ in the unbalanced growth of this bacterium. It is apparent that this treatment of the data is in sharp contrast with the previous model primarily because here we are concerned with the rates of RNA and DNA syntheses underlying the overall cell growth.

\section{MATERIALS AND METHODS}

Strain. Azotobacter vinelandii IAM 1078 (ATCC 9046) was used.

Medium. A modified Burk's medium in which sucrose was replaced with glucose was used. The medium composition was as follows: $5.0 \mathrm{~g}$ glucose, $0.8 \mathrm{~g} \mathrm{~K}_{2} \mathrm{HPO}_{4}, 0.2 \mathrm{~g} \mathrm{KH}_{2} \mathrm{PO}_{4}, 0.2 \mathrm{~g} \mathrm{MgSO}_{4} \cdot 7 \mathrm{H}_{2} \mathrm{O}, 0.2 \mathrm{~g} \mathrm{NaCl}, 0.05 \mathrm{~g}$ sodium citrate, $0.005 \mathrm{~g} \mathrm{FeSO}_{4} \cdot 7 \mathrm{H}_{2} \mathrm{O}, 0.005 \mathrm{~g} \mathrm{Fe}_{2}\left(\mathrm{SO}_{4}\right)_{3} \cdot 3 \mathrm{H}_{2} \mathrm{O}, 0.001 \mathrm{~g} \mathrm{Na} \mathrm{NoO}_{4} \cdot 2 \mathrm{H}_{2} \mathrm{O}$, $0.01 \mathrm{~g} \mathrm{CaCl} \cdot 2 \mathrm{H}_{2} \mathrm{O}, 1,000 \mathrm{ml}$ tap water, $\mathrm{pH} 7.0$ to 7.2 . It was confirmed from the preliminary experiments that sodium citrate in the medium did not act as a carbon source. Glucose was the sole carbonaceous material.

Chemostat (glucose as the limiting substrate). Cells harvested from the logarithmic growth phase in each preculture were inoculated into a jar fermentor (cell suspension inoculated, $300 \mathrm{ml}$ ). The reactor vessel (nominal volume, 29 liter, working volume, 15 to 20 liter) was equipped with a standard 
flat-blade turbine (rotation speed, $750 \mathrm{rpm}$ ). Aeration rate was $2 \mathrm{vvm}$. Temperature was controlled at $30^{\circ}$ throughout this work.

When the cell concentration attained an appropriate level in the batch culture, a supply of the sterile and fresh medium was initiated to start a continuous operation. If a quick check of the cell concentration measured by a photoelectric photometer at $610 \mathrm{~m} \mu$ remained unchanged for at least 2 or 3 cycles, the steady state was assumed. It was confirmed experimentally in our previous study that concentrations of cell mass, $X$, and residual glucose, $S$, and RNA and DNA fractions, $N_{R}$ and $N_{D}$, and so forth remained unchanged, when the steady state was assumed.

Transfer from chemostat to batch. Glucose was given suddenly to the chemostat, thereby releasing the limiting situation. This addition was followed simultaneously by a suspension of the flow of fresh medium into the vessel as shown below.

A concentrate and sterile solution of glucose in tap water (volume, 2 to 6 liters) was added manually and rapidly into the reactor. The concentrate solution of glucose was prepared such that glucose concentration in the vessel immediately after the suspension of the medium flow ranged from 6 to $10 \mathrm{mg} / \mathrm{ml}$.

Since it was feared that some of the inorganic salts in the original Burk's medium might become limiting when glucose concentration in the medium was elevated, an amount of the inorganic salts, five times as concentrate as those in the original medium per liter was dissolved into $100 \mathrm{ml}$ of tap water; the solution was sterilized and added also to the vessel.

Dissolved oxygen level was measured with the Beckman oxygen analyzer (Type 777). The dissolved oxygen concentration was more than $2 \mathrm{ppm}$ all the time during the balanced and unbalanced growth period. Accordingly, the dissolved oxygen was far from a limiting factor in this work. The broth was around 6.8 in $\mathrm{pH}$ value throughout this series of experiments.

Chemical analyses. The cell mass was measured after each sample was processed to a powder-like material; the centrifuged cells were frozen at $-20^{\circ}$ with a mixture of acetone and dry ice, and then dried in a desiccator $(6)$.

The residual glucose was measured by the SoMOGYI or the Glucostat method. RNA and DNA fractions extracted by means of the ScHMIDTTHANNHAUSER-SCHNEIDER method were measured by spectrophotometer at $260 \mathrm{~m} \mu$. To secure the most reliable data of DNA, the WEBB and LEVY method (7) was also used from time to time.

\section{RESULTS}

\section{$C_{R} / C_{D}$ in the balanced growth}

Values of $C_{R} / C_{D}$ for $A$. vinelandii in this balanced growth in the chemostat are plotted against the specific rate, $\mu_{C_{i}}\left(=\mu_{C_{R}}=\mu_{C_{D}}=\mu_{X}\right)$ in Fig. 1 . 


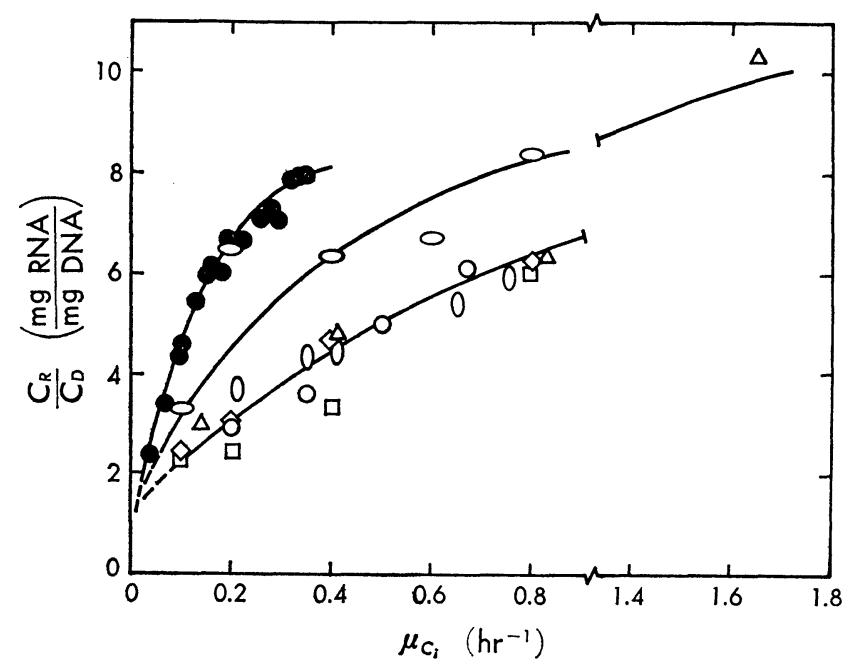

Fig. 1. Ratio of RNA to DNA concentrations, $C_{R} / C_{D}$, against the specific rate, $\mu_{C_{i}}\left(=\frac{1}{C_{i}} \cdot \frac{d C_{i}}{d t}\right)$, during the balanced growth of various bacteria.

- Azotobacter vinelandii, continuous culture, glucose limiting;

Aerobacter aerogenes, batch culture $(8)$;

$\diamond A$. aerogenes, continuous culture, $\mathrm{Mg}^{2+}$-limiting (10);

$\square$ A. aerogenes, continuous culture, glycerol limiting (10);

- A. aerogenes, continuous culture, $\mathrm{K}^{+}$-limiting (11);

0 Escherichia coli, batch culture (9);

$\triangle$ Salmonella typhimurium, batch culture (4).

Additional data on $C_{R} / C_{D}$ ever reported by other workers either in batch (4, $8,9)$ or in the chemostatic culture $(10,11)$ of some bacteria are included in the figure. The batch culture here dealt with the logarithmic growth phase. Solid curves drawn through the data points in Fig. 1 are optional.

It is interesting to remark from Fig. 1 that the data points for these bacteria are represented presumably by respective asymptotes, irrespective of the diversity of culture method and medium composition used. It is difficult to differentiate the curves for Aerobacter aerogenes (excluding the chemostat with $\mathrm{K}^{+}$-limiting), Escherichia coli, and Salmonella typhimurium.

The non-linear asymptote was assumed from Fig. 1 to correlate $C_{R} / C_{D}$ with $\mu_{C_{i}}$ as follows:

$$
\frac{C_{R}}{C_{D}}-\left(\frac{C_{R}}{C_{D}}\right)_{0}=\frac{\mu_{C_{i}}}{\alpha_{2}+\alpha_{1} \mu_{C_{i}}}
$$

subscript: $C_{i}=X, C_{R}$, or $C_{D}$

The value of $\left(C_{R} / C_{D}\right)_{0}$ was at $\mu_{C_{i}}=0$. 


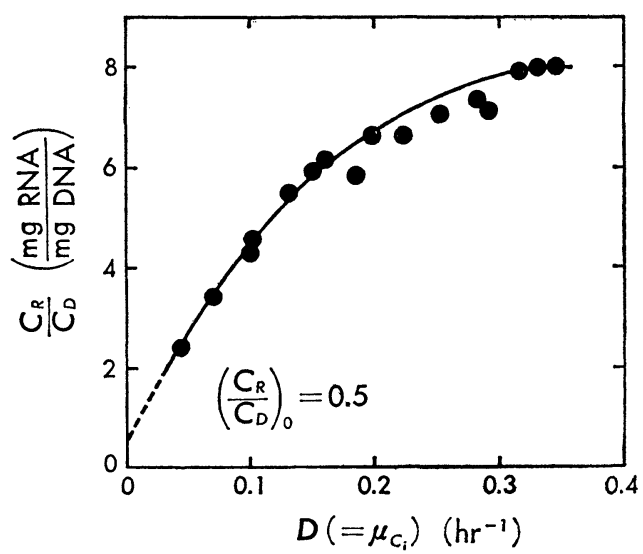

Fig. 2. Ratio of RNA to DNA concentrations, $C_{R} / C_{D}$, against the dilution rate, $D\left(=\mu_{C_{i}}\right)$, for the balanced growth of Azotobacter vinelandii.

According to KJELDGAARD and KURLAND (4), RNA fraction at $\mu_{C_{i}}=0$ in Fig. 1 corresponds to t-RNA. Values of $\alpha_{1}$ and $\alpha_{2}$ in Eq. (1) depend perhaps on the species of bacterium and the culture method used.

Eq. (1) can be rearranged as follows:

$$
\begin{aligned}
& \mu_{C_{i}}=\frac{\alpha_{2}\left\{\frac{C_{R}}{C_{D}}-\left(\frac{C_{R}}{C_{D}}\right)_{0}\right\}}{1-\alpha_{1}\left\{\frac{C_{R}}{C_{D}}-\left(\frac{C_{R}}{C_{D}}\right)_{0}\right\}} \\
& \frac{1}{\mu_{C_{i}}}=\frac{1}{\alpha_{2}}\left\{\frac{1}{\frac{C_{R}}{C_{D}}-\left(\frac{C_{R}}{C_{D}}\right)_{0}}-\alpha_{1}\right\}
\end{aligned}
$$

If Eq. (1) is acceptable, a linear correlation must be obtained between $1 / \mu_{C_{i}}$ and $1 /\left\{C_{R} / C_{D}-\left(C_{R} / C_{D}\right)_{0}\right\}$; the slope of this linear correlation gives the value of $1 / \alpha_{2}$, while an intercept of the straight line from the ordinate represents the value of $-\left(\alpha_{1} / \alpha_{2}\right)$.

In order to clarify the plot of $C_{R} / C_{D}$ against $\mu_{C_{i}}(=D)$ for $A$. vinelandii, Fig. 2 was prepared additionally by using the data points in Fig. 1 . The value of $\left(C_{R} / C_{D}\right)_{0}$ was taken as 0.5 from the intercept in Fig. 2.

The reciprocal of $D$ was plotted against that of $\left(C_{R} / C_{D}\right)-\left(C_{R} / C_{D}\right)_{0}$ in Fig. 3. The linear correlation between the two terms is clear from the figure. Eq. (3) was supported by this linear correlation and the values of $\alpha_{1}$ and $\alpha_{2}$ in Eq. (3) were estimated from this straight line at 0.8 and 0.18 , respectively.

$C_{R} / C_{D}$ in the unbalanced growth

Experimental data regarding $C_{R}, C_{D}$, and $C_{R} / C_{D}$ are shown in Fig. 4. 


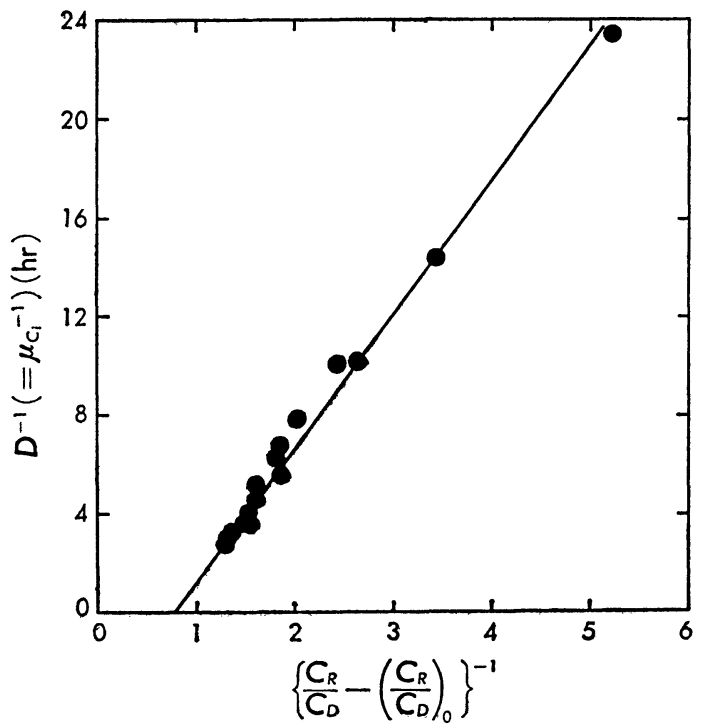

Fig. 3. Reciprocal of dilution rate against that of $\left\{\left(C_{R} / C_{D}\right)-\left(C_{R} / C_{D}\right)_{0}\right\}$ for the balanced growth of Azotobacter vinelandii.

The ordinates represent $C_{R}$ and $C_{D}$ in the logarithmic scale and in addition, $C_{R} / C_{D}$ in the ordinary scale, while the abscissa is time. Glucose was given suddenly to the chemostat at $t=0$ in the figure to realize the unbalanced growth.

Before the addition of glucose at $t=0$, the concentration of the substrate in each chemostat ranged from 1 to $3 \mu \mathrm{g} / \mathrm{ml}$; indeed, glucose in the chemostat limited the growth of this bacterium. Experimental data on the concentration of glucose before and after $t=0$ were omitted.

Different symbols in Fig. 4 demonstrate the difference in dilution rate, $D\left(0.10\right.$ to $\left.0.25 \mathrm{hr}^{-1}\right)$, prior to the sudden pulse of glucose. Solid lines in Fig. 4 were prepared optionally by hand to represent the data points most favorably in each run. Apparently, $C_{R}$ and $C_{D}$ at $t=0$ in the figure stepped down from the steady state values for each dilution rate, because the culture was diluted by adding the concentrate solutions of glucose and inorganic salts.

It is seen from Fig. 4 that the increase of $C_{R} / C_{D}$ is sigmoid and that the values of $C_{R}$ and $C_{D}$ increased logarithmically after particular points as assumed by short and vertical chain-like bars. The ratio, $C_{R} / C_{D}$ could be assumed constant, after these bars.

\section{DISCUSSION}

Analogous to Eq. (2) in which $\mu_{C_{i}}$ was correlated with $C_{R} / C_{D}$ for the 


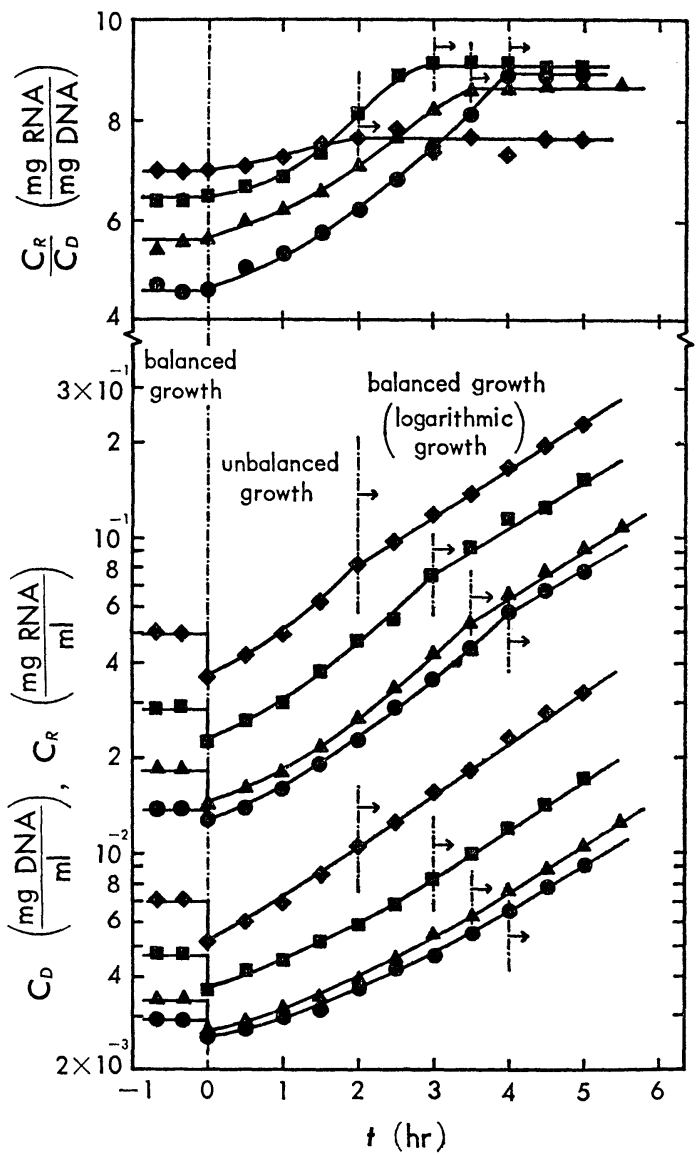

Fig. 4. RNA and DNA concentrations, $C_{R}$ and $C_{D}$, and their ratio plotted against time, $t$, during the balanced and unbalanced growth of Azotobacter vinelandii.

The sudden pulse of glucose was charged at $t=0$ into the culture to disrupt the balanced growth. Different symbols demonstrate the difference in dilution rate, $D\left(0.10\right.$ to $\left.0.25 \mathrm{hr}^{-1}\right)$, prior to the sudden pulse of glucose. - $\mathrm{D}=0.100 \mathrm{hr}^{-1}, \quad \Delta \mathrm{D}=0.148 \mathrm{hr}^{-1}$, $\mathrm{D}=0.196 \mathrm{hr}^{-1}, \quad \mathrm{D}=0.250 \mathrm{hr}^{-1}$.

balanced growth, specific rates of change in $C_{R}$ and $C_{D}$ were assessed from the unbalanced growth data in Fig. 4.

The assessment here was by drawing a tangent to each solid curve at the data points in the figure. Values of $\mu_{C_{R}}$ and $\mu_{C_{D}}$ are shown by plain symbols in Fig. 5. Though this estimate was not necessarily strict, the patterns shown by solid curves in Fig. 5 were confirmed to be least susceptible to change. 


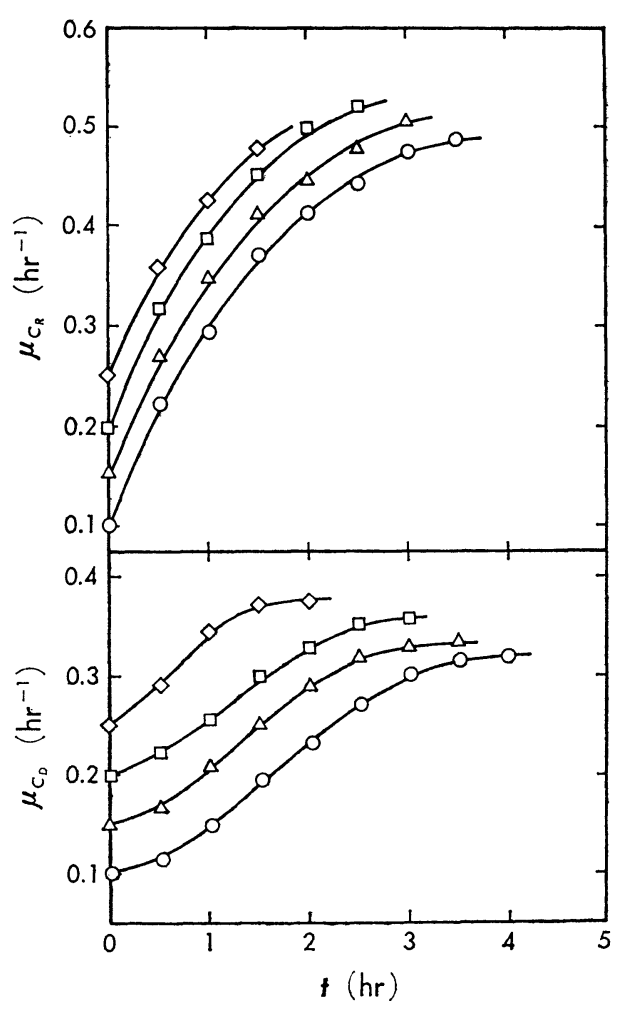

Fig. 5. Values of specific rate of $C_{R}$ and $C_{D}$ plotted against time, $t$.

Different symbols demonstrate the difference in dilution rate, $D$ $\left(0.10\right.$ to $\left.0.25 \mathrm{hr}^{-1}\right)$, prior to the sudden pulse of glucose.

$\bigcirc \mathrm{D}=0.100 \mathrm{hr}^{-1}, \quad \triangle \mathrm{D}=0.148 \mathrm{hr}^{-1}, \quad \square \mathrm{D}=0.196 \mathrm{hr}^{-1}, \diamond \mathrm{D}=0.250 \mathrm{hr}^{-1}$.

It is significant to remark from Fig. 5 that the value of $\mu_{C_{R}}$ increases without delay in the unbalanced growth, whereas the value of $\mu_{C_{D}}$ exhibits an appreciable time lag in responding to the unbalanced situation. Generally, synthesis of RNA precedes that of DNA after the nutritional conditions are shifted up $(8,12,13)$.

Fig. 6 was prepared by cancelling time $t$ from Fig. 5 and from $C_{R} / C_{D}$ in Fig. 4. The broken curve in Fig. 6 is the relationship between $C_{R} / C_{D}$ and the specific rate of change either in $C_{R}$ or $C_{D}$ in the chemostat ( $c f$. Fig. 2). The unbalanced growth was initiated from each particular point on the broken curve in Fig. 6 . Solid curves in the figure were drawn optionally by hand, illustrating a general trend of $C_{R} / C_{D}$ as varied with either $\mu_{C_{R}}$ or $\mu_{C_{D}}$ in the unbalanced growth.

Similar to Eq. (1) for the balanced growth, the following equation was 


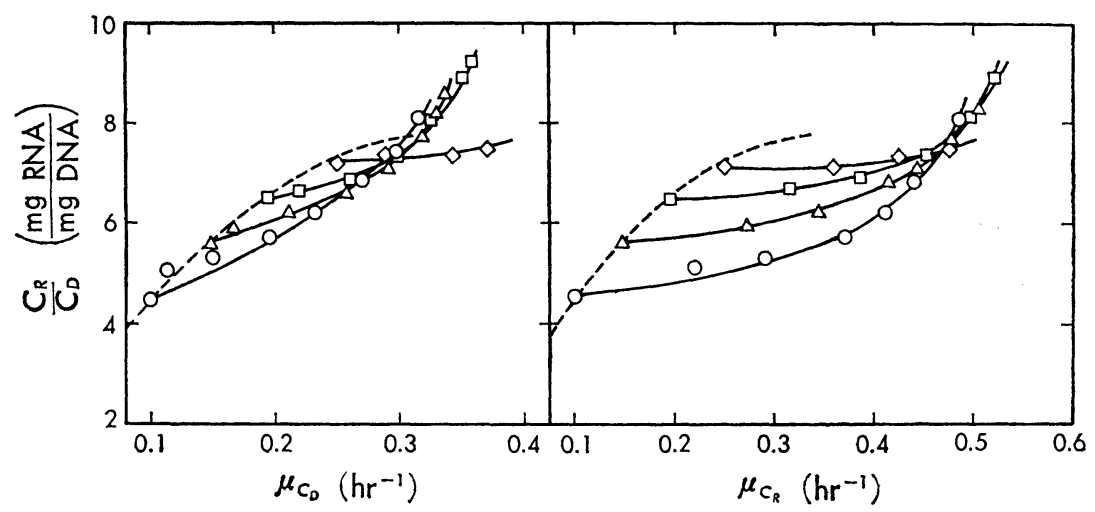

Fig. 6. Ratio of RNA to DNA concentrations, $C_{R} / C_{D}$, vs. specific rates of $C_{R}$ and $C_{D}\left(=\mu_{C_{R}}=\mu_{C}\right)$ during the unbalanced growth.

Different symbols demonstrate the difference in dilution rate, $D\left(0.10\right.$ to $\left.0.25 \mathrm{hr}^{-1}\right)$, prior to the sudden pulse of glucose.
$\mathrm{D}=0.100 \mathrm{hr}^{-1}$,
$\triangle \mathrm{D}=0.148 \mathrm{hr}^{-1}$,
$\mathrm{D}=0.196 \mathrm{hr}^{-1}$,
$\diamond \mathrm{D}=0.250 \mathrm{hr}^{-1}$

assumed to represent the unbalanced growth.

$$
\begin{aligned}
\frac{C_{R}}{C_{D}}-\left(\frac{C_{R}}{C_{D}}\right)_{i} & =\frac{\mu_{C_{R}}}{\alpha_{4}+\alpha_{3} \mu_{C_{R}}} \\
& =\frac{\mu_{C_{D}}}{\alpha_{6}+\alpha_{5} \mu_{C_{D}}}
\end{aligned}
$$

provided: $\left(C_{R} / C_{D}\right)_{i}$ is an initial value of $C_{R} / C_{D}$ for each unbalanced growth. $\alpha_{3}, \alpha_{4}, \alpha_{5}$, and $\alpha_{6}$ are empirical coefficients.

The term $\left\{\left(C_{R} / C_{D}\right)-\left(C_{R} / C_{D}\right)_{i}\right\}$ is considered to imply the synthetic activity, i.e., the adaptability of the cells to the new environment in the unbalanced growth.

Eqs. (4) and (5) can be rearranged as follows:

$$
\begin{gathered}
\mu_{C_{R}}=\frac{\alpha_{4}\left\{\frac{C_{R}}{C_{D}}-\left(\frac{C_{R}}{C_{D}}\right)_{i}\right\}}{1-\alpha_{3}\left\{\frac{C_{R}}{C_{D}}-\left(\frac{C_{R}}{C_{D}}\right)_{i}\right\}} \\
\mu_{C_{D}}=\frac{\alpha_{6}\left\{\frac{C_{R}}{C_{D}}-\left(\frac{C_{R}}{C_{D}}\right)_{i}\right\}}{1-\alpha_{5}\left\{\frac{C_{R}}{C_{D}}-\left(\frac{C_{R}}{C_{D}}\right)_{i}\right\}}
\end{gathered}
$$




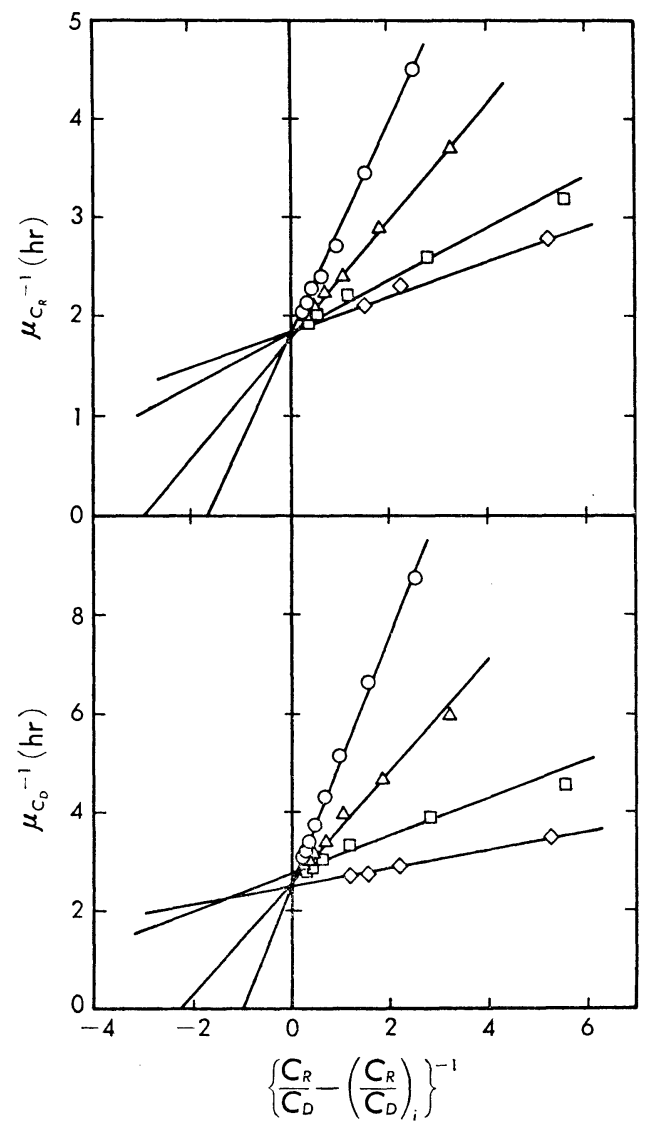

Fig. 7. Reciprocal of $\mu_{C_{R}}$ and $\mu_{C_{D}}$ vs. that of $\left\{\left(C_{R} / C_{D}\right)-\left(C_{R} / C_{D}\right)_{i}\right\}$ during the unbalanced growth.

Different symbols demonstrate the difference in dilution rate, $D$ ( 0.10 to $\left.0.25 \mathrm{hr}^{-1}\right)$, prior to the sudden pulse of glucose.

$\bigcirc \mathrm{D}=0.100 \mathrm{hr}^{-1}, \quad \triangle \mathrm{D}=0.148 \mathrm{hr}^{-1}, \quad \square \mathrm{D}=0.196 \mathrm{hr}^{-1}, \diamond \mathrm{D}=0.250 \mathrm{hr}^{-1}$.

$$
\begin{aligned}
& \frac{1}{\mu_{C_{R}}}=\frac{1}{\alpha_{4}}\left\{\frac{1}{\frac{C_{R}}{C_{D}}-\left(\frac{C_{R}}{C_{D}}\right)_{i}}-\alpha_{3}\right\} \\
& \frac{1}{\mu_{C_{D}}}=\frac{1}{\alpha_{6}}\left\{\frac{1}{\frac{C_{R}}{C_{D}}-\left(\frac{C_{R}}{C_{D}}\right)_{i}}-\alpha_{5}\right\}
\end{aligned}
$$

Values of $\mu_{C_{R}}, \mu_{C_{D}}, C_{R} / C_{D}$ and $\left(C_{R} / C_{D}\right)_{i}$ were taken respectively from plain symbols (not solid curves) in Fig. 6. The reciprocals of $\mu_{C_{R}}$ or $\mu_{C_{D}}$ were 
then plotted against those of $\left\{\left(C_{R} / C_{D}\right)-\left(C_{R} / C_{D}\right)_{i}\right\}$ in Fig. 7.

Eqs. (8) and (9) are supported by the straight lines in the figure. Values of $\alpha_{3}, \alpha_{4}, \alpha_{5}$, and $\alpha_{6}$ could be determined from each diagram in Fig. 7 by using the slope and intercept of these straight lines.

It is noted from Fig. 7 that four intercepts of the straight lines from the ordinate are nearly equal. Here, an analogy assumed between the Lineweaver-Burk plot and the plot in Fig. 7 shows that the intercept corresponds to the reciprocal of the maximum value of $\mu_{C_{R}}$ or $\mu_{C_{D}}$.

Rearrangement of Eqs. (6) and (7) gives

$$
\begin{array}{r}
\mu_{C_{R}}=\frac{\left(\mu_{C_{R}}\right)_{m}\left\{\frac{C_{R}}{C_{D}}-\left(\frac{C_{R}}{C_{D}}\right)_{i}\right\}}{K_{C_{R}}+\left\{\frac{C_{R}}{C_{D}}-\left(\frac{C_{R}}{C_{D}}\right)_{i}\right\}} \\
\mu_{C_{D}}=\frac{\left(\mu_{C_{D}}\right)_{m}\left\{\frac{C_{R}}{C_{D}}-\left(\frac{C_{R}}{C_{D}}\right)_{i}\right\}}{K_{C_{D}}+\left\{\frac{C_{R}}{C_{D}}-\left(\frac{C_{R}}{C_{D}}\right)_{i}\right\}}
\end{array}
$$

where $\left(\mu_{C_{R}}\right)_{m}=-\left(\alpha_{4} / \alpha_{3}\right),\left(\mu_{C_{D}}\right)_{m}=-\left(\alpha_{6} / \alpha_{5}\right), K_{C_{R}}=-\left(1 / \alpha_{3}\right)$, and $K_{C_{D}}=-\left(1 / \alpha_{5}\right)$. These values determined from Fig. 7 are summarized in Table 1. Values of $K_{C_{R}}$ and $K_{C_{D}}$ in the table depend appreciably on the dilution rate prior to the respective unbalanced growth, whereas the values of $\left(\mu_{C_{R}}\right)_{m}$ and $\left(\mu_{C_{D}}\right)_{m}$ are nearly kept intact, respectively.

It is interesting to find that the specific rate of change in RNA and DNA concentration in the unbalanced growth could eventually be shown by Eqs. (10) and (11). A sequence of the optional treatment of the data points such as the assessment of $\mu_{C_{R}}$ and $\mu_{C_{D}}$ by hand in Fig. 4 did not affect the general conclusion at all.

Different aspects of the bacterial growth exhibited the same type of correlation between $C_{R} / C_{D}$ and $\mu_{C}$, if and only if the parameter $C_{R} / C_{D}$ was

Table 1. Values of $K_{C_{R}}, K_{C_{D}},\left(\mu_{C_{R}}\right)_{m}$ and $\left(\mu_{C_{D}}\right)_{m}$ in Eqs. (10) and (11).

\begin{tabular}{c|cc|cc}
\hline $\begin{array}{c}D \\
\left(\mathrm{hr}^{-1}\right)\end{array}$ & \multicolumn{2}{|c|}{ RNA synthesis } & \multicolumn{2}{c}{ DNA spnthesis } \\
\hline 0.100 & $K_{C_{R}}$ & $\left(\mu_{\left.C_{R}\right)_{m}}\right.$ & $K_{C_{D}}$ & $\left(\mu_{\left.C_{D}\right)_{m}}\right.$ \\
\hline 0.148 & 0.61 & 0.55 & 1.00 & 0.39 \\
0.196 & 0.33 & 0.56 & 0.44 & 0.40 \\
0.250 & 0.14 & 0.54 & 0.14 & 0.35 \\
\hline
\end{tabular}

$D$ : Dilution rate before transfer from balanced to unbalanced growth, $K_{C_{R}}:-\left(1 / \alpha_{3}\right), K_{C_{D}}:-\left(1 / \alpha_{5}\right), \quad\left(\mu_{C_{R}}\right)_{m}:-\left(\alpha_{4} / \alpha_{3}\right), \quad\left(\mu_{C_{D}}\right)_{m}:-\left(\alpha_{6} / \alpha_{5}\right)$. 
defined properly as in Eq. (1) or Eq. (4) (Eq. (5)). The only change depending on balanced and unbalanced growth of this bacterium was in the signs and absolute values of the coefficients involved in these kinetic equations.

Thanks are due to M. Onodera, and M. Hamazaki for their technical assistance.

\section{REFERENCES}

1) S. Nagai, Y. Nishizawa, I. Endo and S. Aiba, J. Gen. Appl. Microbiol., 14, 121 (1968).

2) M. Schaechter, O. MaAl $\phi$ E and N.O. KJeldgaARd, J. Gen, Microbiol., 19, 592 (1958).

3) I.A. Khmel and N.B. Andreen, Mikrobiol., 36, 438 (1967).

4) N.O. KJeldgaArd and C.G. Kurland, J. Mol. Biol., 6, 341 (1963).

5) S. Aiba, S. Nagai, Y. Nishizawa and M. Onodera, J. Gen. Appl. Microbiol.,'13, 85 (1967).

6) S. Aiba, S. Nagai, Y. Nishizawa and M. Onodera, J. Gen. Appl. Microbiol., 13, 73 (1967).

7) J.M. WebB and H.B. Levy, J. Biol. Chem., 213, 107 (1955).

8) F.C. Neidhardt and B. Magasanik, Biochim. Biophys. Acta, 42, 99 (1960).

9) R. Rosset, R. Monier and J. Julien, Biochem. Biophys. Res. Commun., 15,329 (1964).

10) D.W. Tempest, J.R. Hunter and J. Sykes, J. Gen. Microbiol,, 39, 355 (1965).

11) D.W. Tempest, J.W. Dicks and J.R. Hunter, J. Gen. Microbiol., 45, 135 (1966).

12) N.O. KJeldgaARd, O. MaAl $\phi$ E and M. Schaechter, J. Gen. Microbiol., 19, 607 (1958).

13) N.O. KJeldgaArd, Biochim. Biophys. Acta, 49, 64 (1961). 